\title{
Editorial: The role of CRM in changing and facilitating competitive advantage
}

Over the past 20 years I have been studying how better information and information systems might improve business efficiency and effectiveness. Over this time our understanding of the nature of business systems has improved, as has our understanding of the nature of markets.

The problems companies have when trying to implement new systems and procedures have not, however, changed. In the 1980s, there was increasing evidence that the move to the strategic use of information technology (IT) would not be as easy or successful as early writers had implied. In the 1990s, as CRM gained attention, many practitioners and IT specialists seemed to have forgotten some of these lessons. Marketing managers reported difficulty in making strategic use of information systems, partly due to inadequacies of the IT systems when matched with the special needs of marketing strategy, but also because of a lack of strategic focus in companies.

In the new millennium little seems to have changed. In Journal of Database Marketing Vol. 9, No. 1, one author, Neil Woodcock, began his paper with the comment 'Most CRM projects are likely to fail'. This was based on predictions from various studies. Why is it that despite our increased understanding the problems remain the same and the majority of applications do not seem to justify the initial investment and cannot be deemed successful? Is it poor understanding of direct marketing principles, relationship marketing methods or strategic thinking? Is the new technology causing unexpected difficulties, or are human and organisational problems causing difficulties in planning and integration?

My own research has shown that the reasons behind a positive adoption decision were conceptually different from usage, with firms' perceptions of barriers and constraints to customer relationship management (CRM) deployment changing as they gained experience of applications. Thus a system or process which might be suitable for bringing a company to a position where it might use CRM is not necessarily the best system or process for ensuring its successful use. The effective use of a sophisticated CRM system is achieved by matching organisational capabilities and market context, rather than by uncritical adoption and development. Sophisticated CRM management is strategically oriented and integrated with a company's competitive strategy.

A general conclusion is that although organisational and strategic barriers are more important than technical barriers this is frequently not recognised by the adopting firm. Organisational barriers relate to structural issues, such as fragmentation and poor relationships and communication across departments. Strategic barriers include a lack of acceptance by senior management of the strategic benefits of CRM intervention and a lack of a clear strategy for CRM implementation. My research concluded that organisations have yet to learn that 
the adoption of new technologies such as CRM, which lead to fundamental change, requires a much greater focus on the strategic and organisational implications of the intervention. While there will be a focus on the immediate problems of technological incompatibility and cost containment this is only part of the problem.

Much of the literature on adoption of IT innovations shows that overcoming technical barriers is not as important in the development of sophisticated systems as the need to restructure information flows and increase customer data capture. Both of these call for a redefinition of tasks and responsibilities and increased communication across functional boundaries. In many firms there is now a substantial degree of integration between the IT and marketing functions, and both are highly involved in strategic decision making. In many firms, however, there is still a lack of strategic coherence, no long-term time frame for investment decisions, no company-wide marketing orientation and low strategic importance given to direct and CRM activities, compared to traditional marketing practices.

In 1996, I commented that the promise of these systems to deliver competitive advantage would be compromised, as indeed now seems to be happening. The philosophy of many firms seems to be that because the technology exists they should use use it, rather than considering the competitive advantage that can be gained from the use of information. Firms' ability to enter the strategic IT phase will depend on three elements: the existing level of IT operations and the strategic and organisational context within which decisions are made and implemented. CRM requires a set of pre-existing marketing skills and attitudes and the ability to collect and manage large quantities of data. Both these critical success factors are themselves embedded in an enabling strategic and organisational context.

The papers selected for this special issue reflect these concerns. Kendrick and Fletcher argue that many CRM processes are too rigid and distort strategy. The paper introduces and examines the concept of customer myopia, which is over-reliance on the existing customer base rather than a study of the whole market of potential customers. Eight illustrative assumptions are studied and it is hoped that these will form the basis for further discussion about the application of CRM. Used in an unsophisticated way both marketing planning and CRM approaches have the potential to deflect attention from good marketing management in companies. A close CRM-driven analysis of the current customer base is crucial to effective business planning but for sound business planning this should also be in the context of a wider marketing planning process which integrates all elements. The authors put the argument for a strategic perspective and the need to align CRM and marketing planning approaches - they advocate strategic interactive marketing planning (SIMP) as a response.

Lynette Ryals continues with a paper which highlights an important issue in marketing, the lack of measurement and metrics available to marketers. Lynette suggests that the customer base be used as an investment portfolio in which some customers will repay additional investment. While this general approach is recognised when building lifetime value, the paper is novel in that it uses the portfolio management model of risk and return to explore the measurement of returns and customer risk. (Customer risk is the risk that the customer segment will not perform as expected, through 
defections or changed buying patterns.) The model is presented clearly and a method for assessing customer risk and returns is described. A risk scorecard is suggested to help managers develop strategies to create value from a portfolio of customers or customer segments.

Plakoyiannaki and Tzokas present a framework to implement CRM from which they develop core CRM capabilities. They describe a holistic approach that stresses the need to create a learning organisation if the necessary market orientation is to be developed. Integration and alignment are also essential for interfunctional coordination of IT and information sharing. Finally, strategic focus gives organisational direction (based on the mission statement of core values).

The next paper investigates the way the Web is influencing direct marketing. Alan Tapp takes a critical view of the claims made for the Web and looks at the probable changes in customer behaviour, rise of infomediaries and the influence of information flows on value chains. His suggestion of a mixture of reactive and proactive marketing, with both consumers and suppliers interchanging empowerment, is surely the route for the future. This will contribute to the rise of 'interactive' marketing, which is an integration of database marketing, CRM and Web-based marketing. This recognises the many points of contact that are possible and that influence and power reside in different sides of the exchange process at different times.

One of the constant concerns over the years is that managers have plenty of data but do not know what to do with it! With CRM the availability of customer information has grown but many companies still do not have the basic systems necessary to ensure they capitalise on this information. Roger Luxton's paper outlines the case for a marketing strategy, which attempts to avoid this, and argues for important steps to avoid the typical mistakes.

Another concern over the years has been the need for integrated communication management and the paper by Hansotia and Rukstales explores the challenges that companies with multiple channels face in ensuring an integrated consumer viewpoint. Within this environment, the retailer is often drowning in customer level transaction data and the paper discusses how this data can be converted into information to make smart direct marketing decisions, and how analytical tools can be leveraged to maximise customer performance.

Despite the concerns of previous authors Starkey and Woodcock point out that the relationship between customer management and business performance is proven. However, companies are again losing economic value for a number of reasons. Using the CMAT model they report on their findings and suggest many improvements in management processes, rather than CRM, in order to increase value. Clearly, what is required is an implementation framework that incorporates an understanding of current capability and places this within a strategic marketing framework, as suggested by the two papers included in this special edition.

The final paper is by Donaldson and Wright and focuses on information systems and sales force automation. These systems have a higher than normal failure rate. The paper builds on previous work which investigated the adoption of database marketing in the financial services sector. They argue that while many systems are in use they are not being used to the full. Typically, they are tactical and use an acquisition rather than relationship approach in building marketing objectives. The reality of the 
way the systems are used in practice is reflected in the extent and degree of measurement of sales results and the actual information held on these sophisticated systems - these cannot underpin the achievement of high-level strategic objectives.

These papers show a mixed view of the strategic use of CRM. While CRM could achieve major strategic objectives, the failure to do so is often down to management inadequacies, rather than a failure in the systems. CRM is not a magical cure-all for gaining strategic advantage, but the papers show how long-term advantage could be gained over competitors. As with many other new approaches it is likely that when the fuss has died down many of the best ideas will be retained and integrated with proven methods, and the bad ideas will be forgotten. The difficulty is knowing which is which.

KEITH FLETCHER

Professor of Management University of East Anglia, UK

December 2001 